\title{
Assessment of anti-reflux treatment on pulmonary ventilation function and inflammatory cytokines in patients with stable chronic obstructive pulmonary disease combined with gastroesophageal reflux
}

\author{
HANG LIU \\ Department of Respiratory Medicine, People's Hospital of Guangxi Zhuang Autonomous Region, \\ Nanning, Guangxi Zhuang Autonomous Region 530022, P.R. China
}

Received October 9, 2017; Accepted March 16, 2018

DOI: $10.3892 /$ etm.2018.6077

\begin{abstract}
Compelling evidence has demonstrated that systemic inflammation among patients with stable chronic obstructive pulmonary disease (COPD) is linked with increased levels of inflammatory cytokines. The aim of the present study was to investigate the effects associated with anti-reflux treatment on pulmonary ventilation function and inflammatory cytokines in patients with stable COPD and gastroesophageal reflux (GER). One hundred and thirty-six stable COPD and GER patients were recruited for the study and randomly designated into the routine treatment and the anti GER groups. Six months prior to and after treatment, pulmonary ventilation function, 6-min walk distance (6MWD) and times of acute exacerbation of COPD (AECOPD) were recorded. The levels of inflammatory cytokines IL-13, IL-18, transforming growth factor- $\beta 1$ (TGF- $\beta 1$ ) and tumor necrosis factor- $\alpha$ (TNF- $\alpha)$ in the sputum were detected by ELISA. BODE indexes, including body mass index, obstruction, dyspnea and exercise, were analyzed in order to evaluate patient prognoses. In comparison with the routine treatment group, patients in the anti-GER group displayed improved pulmonary ventilation function, increased 6MWD as well as decreases in AECOPD, levels of IL-13, IL-18, TGF- $\beta 1$ and TNF- $\alpha$ in the sputum and BODE index 6 months after treatment. The results obtained suggested a correlation between the BODE indexes after treatment and the course of disease as well as the frequency of exacerbation. The key findings of the study suggested that conventional treatment
\end{abstract}

Correspondence to: Dr Hang Liu, Department of Respiratory Medicine, People's Hospital of Guangxi Zhuang Autonomous Region, 6 Taoyuan Road, Nanning, Guangxi Zhuang Autonomous Region 530022, P.R. China

E-mail: dr_liuhang@163.com

Key words: anti-reflux treatment, gastroesophageal reflux, chronic obstructive pulmonary disease, pulmonary ventilation function, inflammatory cytokines combined with anti-reflux treatment could effectively improve pulmonary ventilation function, while acting to decrease the levels of inflammatory cytokines and improve the prognosis of patients with stable COPD along with GER.

\section{Introduction}

Chronic obstructive pulmonary disease (COPD) represents a frequently occurring chronic respiratory condition, with its primary pathological manifestation exhibited characterized by expiratory airflow limitation (1). Clinical statistical data has indicated that COPD ranks fourth worldwide in regard to its mortality rate and fifth with in relation to the future burden of disease (by 2020) (2). COPD generally observed amongst older individuals aged $\geq 75$ years. Furthermore, the exacerbation of COPD remains a large risk factor resulting in hospitalization and increasing mortality rates (3). It is widely accepted in concert with literature, that COPD is caused by chronic airway inflammation with a strong correlation to tobacco smoking as well as inhalation of foreign particles (4). COPD awareness is growing, educating people about airway inflammation as the foremost cause of COPD, with the markers of systemic inflammation being entirely responsible for the deaths amongst COPD patients, including that of tumor necrosis factor (TNF)- $\alpha$, interleukin 6 (IL-6) and IL-8 (5). COPD patients commonly experience both physiological and pathological changes, including increases in respiratory center drive, gastric and negative intrathoracic pressure, as well as abnormally high levels of pulmonary inflammation (6). Interestingly, recent years have brought with them several symptoms of gastroesophageal reflux (GER) in combination in patients suffering from chronic respiratory diseases (7).

GER is one of the most common gastrointestinal-related outpatient diagnoses, associated with a series of symptoms including, chest pain, acid regurgitation, heartburn and food reflux (8). The gold standard in regard to the diagnosis of GERD, is comprised of a $24 \mathrm{~h}$ esophageal $\mathrm{pH}$ monitoring system which is applied in a variety of approaches (9). At present, the general GER treatment approach revolves around acid suppression, anti-reflux drug, maintenance therapy, and 
antacids (10). Furthermore, anti-secretion represents the chief treatment tool for GER, comprised of $\mathrm{H} 2$ receptor antagonists (H2RA) and proton pump inhibitors drug (PPI) (11). Several previous studies have demonstrated the significant association shared between GER and the exacerbation of COPD $(11,12)$, indicating that GER as a potential complication of COPD. However, insignificant research has been performed investigating the impact of anti-reflux treatment for patients with stable COPD in combination with GER from a pulmonary ventilation function and inflammatory cytokine level perspective. Hence, the present study aimed to investigate the effects of the anti-reflux treatment on pulmonary ventilation function and inflammatory cytokines in patients with stable COPD and GER.

\section{Materials and methods}

Ethical statement. All participating subjects signed written informed consent documents. The present study was performed with the approval of the Ethical Committee of the People's Hospital of Guangxi Zhuang Autonomous Region.

Study subjects. Between July 2014 and November 2015, a total of 136 patients suffering from both COPD and GER (100 males and 36 females; mean age: 55.85 \pm 8.29 years; mean course of disease: $6.46 \pm 1.54$ years) who had been admitted to the People's Hospital of Guangxi Zhuang Autonomous Region were recruited for the purposes of the study. The patients were randomly divided into either the routine treatment group (receiving conventional treatment) or the anti GER group (receiving conventional treatment and anti-reflux treatment). The routine treatment group comprised of 70 subjects (53 males and 17 females) with a mean age of $54.89 \pm 8.23$ years, while the anti GER group comprised of 66 subjects (47 males and 19 females) with a mean age of $56.86 \pm 8.29$ years. The subject inclusion criteria was as follows: patients diagnosed with stable COPD based on the Global Initiative for Chronic Obstructive Lung Disease (http://www.goldcopd.com); patients with positive GER, namely reflux esophagitis (RE); patients with Barrett esophagus; patients with typical symptoms such as heartburn or acid reflux $(13,14)$; or patients with a DeMeester score $>14.72$ following a $24-\mathrm{h}$ gastric esophageal $\mathrm{pH}$ monitoring (15); The exclusive criteria for subjects were as below: Patients of Chinese Han ethnicity; patients with stable or mild symptoms of cough, sputum and dyspnea; patients who had previously recovered from an acute exacerbation of COPD. The exclusion criteria for subjects were as follows: Minority and foreign patients; patients with other lung and heart diseases, including disease like lung tumor, asthma, congestive heart failure (CHF), bronchiectasis, tuberculosis; patients with upper and lower respiratory tract infections in the first 2 months before the date of study; patients with PPI treatment at 2 weeks prior to the visit; or patients with steroid hormone treatment 4 weeks prior to the visit.

Routine treatment. Patients in the routine treatment group received conventional treatments, including anti infection, eliminating phlegm and airway dilatation. Non-drug therapy: All patients were required to comply with an smoking cessation policy, take part in physical activity and pulmonary rehabilitation, and avoid personal exposure to occupational dust, smoke and air pollution. Drug therapy: Patients were treated with $\beta 2$ receptor agonist salbutamol (Changzhou Yabang Pharmaceutical Co., Ltd., Changzhou, China), were asked to inhale corticosteroids (ICS) and fluticasone propionate (GlaxoSmithKline Company, London, UK); salbutamol administration was controlled and administered at a dosage of 0.1 0.2 mg 4 6 times a day; the dosage for fluticasone propionate was 500 ug 2 times a day.

Anti-reflux treatment. Patients in the anti GER group received additional anti-reflux treatment in conjunction with their conventional treatment programs. The primary regimen involved a combination of acid suppression and prokinetics. The patients were administrated oral antacid (PPI omeprazole; Harbin Pharmaceutical Pharmaceutical Group Sanjing Pharmaceutical Nuojie Co., Ltd., Harbin, China), at a dosage of $40 \mathrm{mg}$ per day over a 6-month period, along with oral prokinetics mosapride (Shanghai Sine Pharmaceutical Co., Ltd., Shanghai, China), $5 \mathrm{mg}$ per day. Detection of pulmonary ventilation function. All patients underwent a pulmonary ventilation function examination before and 6 months after treatment using a spirograph (Jeager Company, Germany). Patients were placed in a seated position and were asked to inhale $400 \mu \mathrm{g}$ of ventolin, $15 \mathrm{~min}$ after which they were examined between 3 and 5 times repeatedly. The optimal value obtained was used for analysis. The measured parameters included forced vital capacity (FVC), forced expiratory volume in one second (FEV1), the ratio of FVC in the normal reference value $(\mathrm{FVC} \%)$ and the ratio of FEV1 in the normal reference value (FEV1\%). The results were presented in the form of percentages in relation to the recorded values as well as reference values.

Enzyme-linked immunosorbent assay (ELISA). Sputum was collected 6 months before and after treatment, and shaken at 3,000 rpm for $15 \mathrm{~min}$. The supernatant was retrieved for inflammatory cytokine detection. IL-13 and TGF- $\beta 1$ ELISA kits were acquired from Shanghai Bio-Tech Co., Ltd. (Shanghai, China), while tumor necrosis factor $\alpha$ (TNF- $\alpha)$ and IL-18 ELISA kits were acquired from Shenzhen Juying Biotechnology Co., Ltd. (Shenzhen, China). EILSA application processes were conducted in accordance with the instructions, with the intraand inter-assays maintained within a range of $10 \%$. Finally, the absorbance value was read by a spectrophotometer (Thermo Fisher Scientific, Inc., Waltham, MA, USA) at the wavelength of $450 \mathrm{~nm}$ with a wavelength of $620 \mathrm{~nm}$ employed as the reference value.

Collection of bronchoalveolar lavage fluid and inflammatory cell detection. All patients were intramuscularly injected with $0.5 \mathrm{mg}$ of atropine prior to bronchoscopy and bronchoalveolar lavage applications, 6 months before and after treatment. Local anesthesia of the airway was conducted using a $1 \%$ lydocaine solution. A total of $20 \mathrm{ml}$ sterile normal saline was used to lavage the third or fourth sub-segmental bronchus. The lavage fluid was removed as much as possible (the recovery was about 50\%). Bronchoalveolar lavage was processed gently and carefully in order minimizes the pain experienced by 
Table I. Baseline characteristics of COPD patients in the routine treatment and anti GER groups.

\begin{tabular}{|c|c|c|c|}
\hline Variables & Routine treatment group $(\mathrm{n}=70)$ & Anti GER group $(n=66)$ & P-value \\
\hline Age (years) & & & 0.835 \\
\hline$\leq 55$ & 38 & 37 & \\
\hline$>55$ & 32 & 29 & \\
\hline Sex & & & 0.595 \\
\hline Male & 53 & 47 & \\
\hline Female & 17 & 19 & \\
\hline Course of disease (years) & $6.39 \pm 1.61$ & $6.53 \pm 1.48$ & 0.598 \\
\hline Smoke (yes/no) & $50 / 20$ & $48 / 18$ & 0.866 \\
\hline BMI & & & 0.308 \\
\hline$\leq 21$ & 39 & 31 & \\
\hline$>21$ & 31 & 35 & \\
\hline $\mathrm{PaCO}_{2}(\mathrm{mmHg})$ & & & 0.118 \\
\hline$\leq 40$ & 36 & 32 & \\
\hline$>40$ & 34 & 34 & \\
\hline $\mathrm{PaO}(\mathrm{mmHg})$ & & & 0.636 \\
\hline$\leq 60$ & 27 & 22 & \\
\hline$>60$ & 43 & 44 & \\
\hline Plasma albumin $(\mathrm{g} / \mathrm{l})$ & $34.30 \pm 0.53$ & $34.20 \pm 0.51$ & 0.265 \\
\hline Times of AECOPD (times/year) & $3.0 \pm 1.3$ & $2.6 \pm 1.2$ & 0.065 \\
\hline
\end{tabular}

AECOPD, acute exacerbation of chronic obstructive pulmonary disease; BMI, body mass index; GER, gastroesophageal reflux.

the patients. Sputum, blood and carbon foam samples were unqualified. The qualified lavage fluid was placed in an ice box and was quickly sent to laboratory for centrifugation. After centrifugation at 2,000 r/min for $15 \mathrm{~min}$, the supernatant was removed and the subsided cells were kept for subsequent experiments. The subsided cells were re-suspended above $1 \mathrm{ml}$ normal saline. Using a small amount of subsided cells, the total numbers of cells were then counted using a blood cell counting plate. Meanwhile, smear and Wright's staining methods were conducted using a small amount of cells. According to their morphological characteristics, 500 cells were counted respectively at high magnification as monocyte, lymphocyte, eosinophil and neutrophil cells. After counting, the respective percentages were also calculated.

Test of 6-minute walking distance (6MWD). In accordance with the American Thoracic Society guidelines (16), using a 30 meters long straight aisle with three chairs in the middle and the ends of the aisle (as a marked position or resting place for subjects), patients were asked to walk back and forth in order to record 6MWD after becoming familiar with the test environment and process. During the test procedure, the respiratory rate, heart rate, as well as blood pressure of the subjects were carefully monitored. The test was immediately terminated in the event that any symptoms of dizziness, along with anhelation and other symptoms were observed among the subjects.

Acute exacerbation of COPD (AECOPD). AECOPD was confirmed in patients who suffered from short-term continuous deterioration beyond daily conditions along with the following symptoms, including cough and wheezing, purulent sputum, increased sputum secretion, severe fever, insomnia, fatigue, depression or sleepiness, mental disorders, and body discomfort. A decline in exercise tolerance and (or) chest image abnormalities were deemed to be significant signs of AECOPD. The diagnosis criteria of AECOPD were as follows: 1) patients with aggravated anhelation; 2) patients with increased sputum secretion: 3) patients with purulent sputum. Patients diagnosed with at least two conditions of the aforementioned criteria were subsequently diagnosed with AECOPD.

Body mass index (BMI), obstruction, dyspnea, exercise $(B O D E)$ index. The BODE index has been demonstrated to be a crucial indicator in the evaluation of the prognosis of patients with COPD. A greater BODE index indicated a worse prognosis of patients. Patient BODE indexes were monitored (17) before and after 6 months of treatment among the COPD patients. The grading criteria were as follows: The value of BMI (B) $>21 \mathrm{~kg} / \mathrm{m}^{2}$ recorded as 0 point, $\leq 21 \mathrm{~kg} / \mathrm{m}^{2}$ as 1 point; airflow obstruction $(\mathrm{O}) \mathrm{FEV} 1 \% \geq 65 \%$ recorded as 0 point, $50-64 \%$ as 1 point, $36-49 \%$ as 2 points and $\leq 35 \%$ as 3 points; $6-\mathrm{m}$ in walking distance $\geq 350 \mathrm{~m}$ recorded as 0 point, 250-349 $\mathrm{m}$ as 1 point, $150-249 \mathrm{~m}$ as 2 points and $\leq 149 \mathrm{~m}$ as 3 points; dyspnea index (D) $0-1$ recorded as 0 point, 2 as 1 point, 3 as 2 points and 4 as 3 points.

Statistical analysis. Data were analyzed using SPSS v21.0 (IBM Corp., Armonk, NY, USA). Data that was continuously measured data was presented as mean \pm standard deviation, and one-way ANOVA followed by the LSD test was performed 


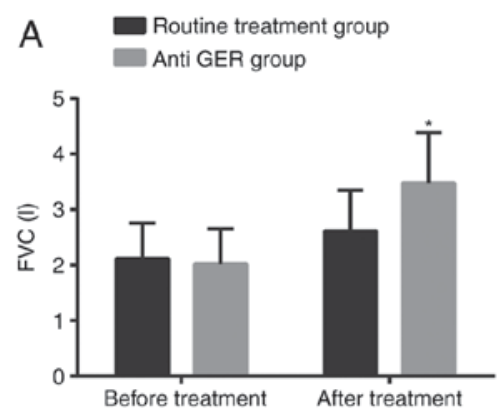

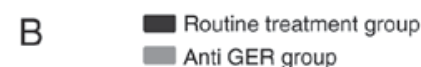

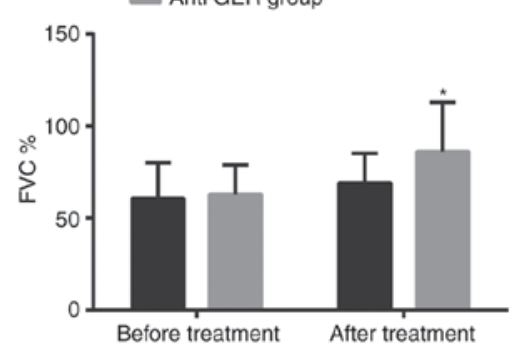

C $\square$ Routine treatment group
Anti GER group

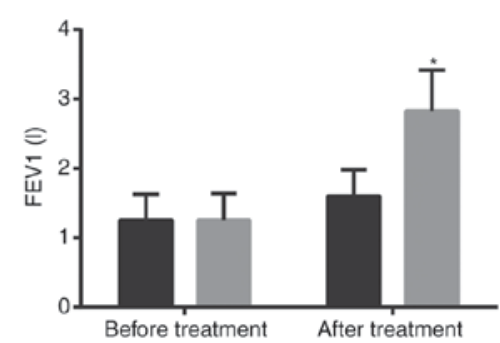

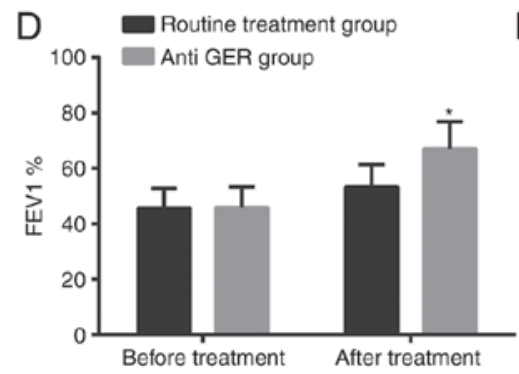

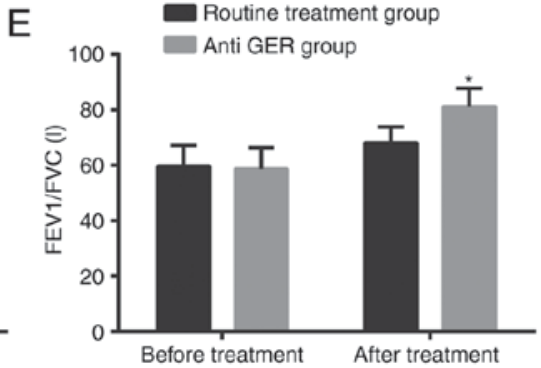

Figure 1. Pulmonary ventilation function in the anti GER group was higher than in the routine treatment group after treatment. (A) Comparison of FVC (L); (B) comparison of FVC\%; (C) comparison of FEV1 (L); (D) comparison of FEV1\%; (E) comparison of FEV1/FVC (L); *P<0.05 compared to the routine treatment group; ${ }^{\#} \mathrm{P}<0.05$ compared to before treatment. GER, gastroesophageal reflux; FVC, forced vital capacity; FEV1, forced expiratory volume in one second.
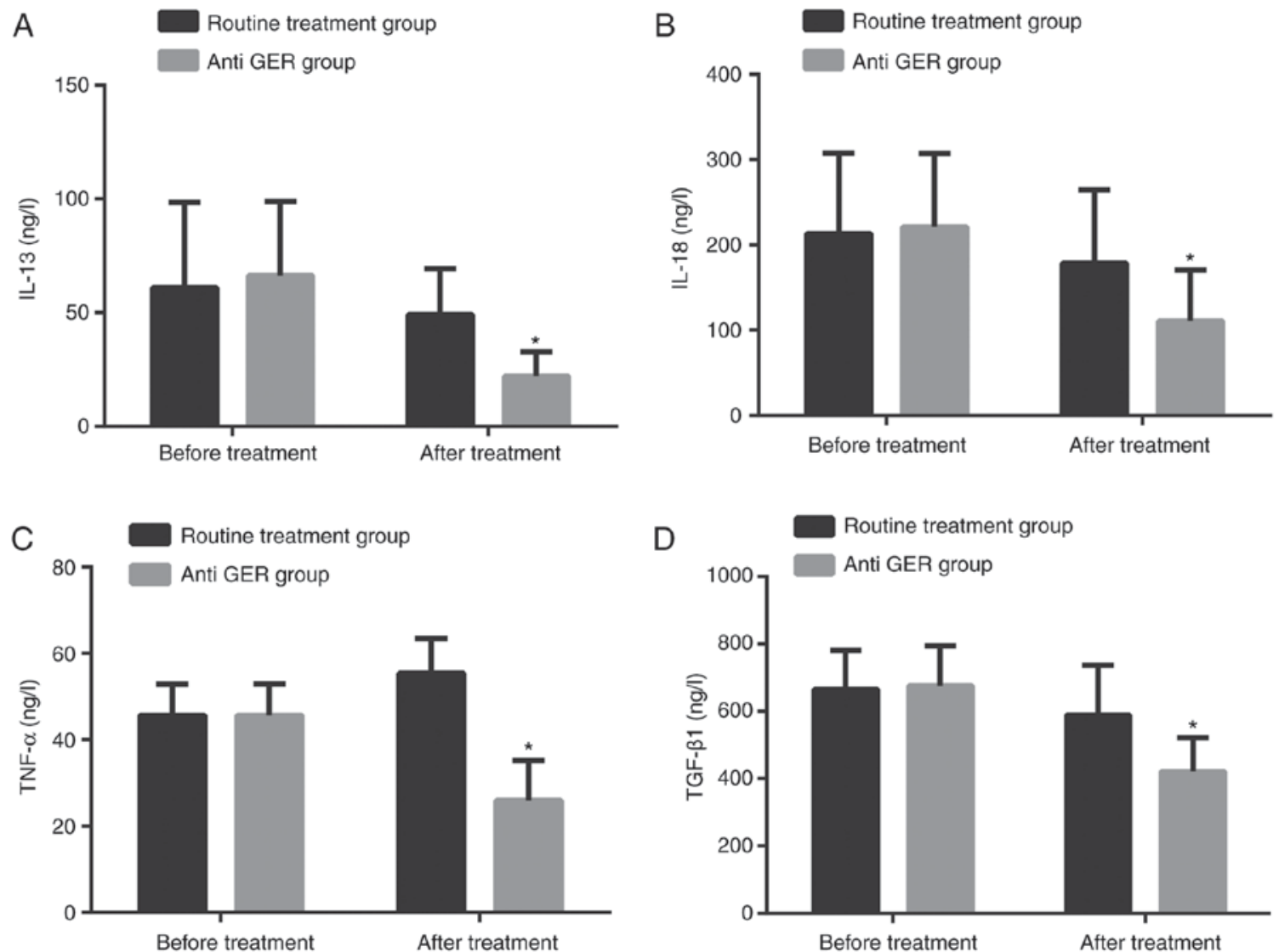

Figure 2. Inflammatory cytokines in the anti GER group were lower than in the routine treatment group after treatment. (A) Comparison of IL-13; (B) comparison of IL-18; (C) comparison of TGF $\beta 1$; (D) comparison of TNF $\alpha$; ${ }^{*} \mathrm{P}<0.05$ compared to the routine treatment group. GER, gastroesophageal reflux; IL, interleukin; TGF- $\beta 1$, transforming growth factor $\beta 1$; TNF- $\alpha$, tumor necrosis factor $\alpha$.

for multiple group comparisons. Categorical data was presented in terms of specific numerical cases, and analyzed by chi-square test. $\mathrm{P}<0.05$ was considered to indicate a statistically significant difference. 
Table II. The total number of inflammatory cells and percentage of eosinophil cells of patients were lower with higher percentages of monocyte, lymphocyte, and neutrophil cells in the anti GER group after treatment.

Cell percentage $(\%)$

\begin{tabular}{lccccc} 
Group & $\begin{array}{c}\text { Total inflammatory } \\
\text { cells }(10-8)\end{array}$ & Lymphocyte & Neutrophil & Eosinophil & Monocyte \\
\cline { 4 - 6 } Routine treatment group & & & & & \\
$\quad$ Before treatment & $4.64 \pm 0.36$ & $3.91 \pm 0.24$ & $20.25 \pm 1.15$ & $8.89 \pm 0.46$ & $49.12 \pm 2.97$ \\
$\quad$ months after treatment & $2.85 \pm 0.15^{\mathrm{a}}$ & $5.76 \pm 0.46^{\mathrm{a}}$ & $28.34 \pm 1.61^{\mathrm{a}}$ & $6.74 \pm 0.51^{\mathrm{a}}$ & $56.75 \pm 3.30^{\mathrm{a}}$ \\
Anti GER group & & & & \\
$\quad$ Before treatment & $4.53 \pm 0.37$ & $3.82 \pm 0.29$ & $20.48 \pm 2.02$ & $8.56 \pm 0.54$ & $50.13 \pm 3.18$ \\
$\quad$ months after treatment & $2.41 \pm 0.19^{\mathrm{a}, \mathrm{b}}$ & $7.49 \pm 0.63^{\mathrm{a}, \mathrm{b}}$ & $36.11 \pm 2.27^{\mathrm{a}, \mathrm{b}}$ & $4.21 \pm 0.32^{\mathrm{a}, \mathrm{b}}$ & $65.33 \pm 4.82^{\mathrm{a}, \mathrm{b}}$ \\
\hline
\end{tabular}

${ }^{a} \mathrm{P}<0.05$ compared with patients before treatment. ${ }^{\mathrm{b}}$ Compared with the routine group.

\section{Results}

Baseline characteristics of patients with COPD between the routine treatment group and anti GER group. As shown in Table I, no significant differences were observed in terms of age, gender, course of disease, smoke, $\mathrm{BMI}, \mathrm{PaCO}_{2}, \mathrm{PaO}$, plasma albumin and AECOPD incidents between the routine treatment group and anti GER group and the results of both groups were comparable (all $\mathrm{P}>0.05$ ). The routine treatment group consisted of 70 patients, including 50 smokers, among whom 49 individuals were confirmed to have adhered to the smoking cessation requirement of the study. The anti GER group comprised of 66 patients, including 48 smokers, among whom 42 people were able to maintain the smoking cessation status during the test. There was no significant difference detected in relation to the number of smokers between the two groups at baseline. Out of the 136 patients, 25 experienced esophagitis, while 3 patients suffered from Barrett esophagus. No adverse reaction in the routine treatment group was observed, and only 1 patient experienced symptoms of nausea and vomiting in the anti GER group.

Pulmonary ventilation function of patients in the anti GER group was higher than in the routine treatment group after treatment. Pulmonary ventilation function was examined before treatment and 6 months after treatment (Fig. 1). Prior to treatment, no significant differences were observed in parameters $[\mathrm{FVC}(\mathrm{L}), \mathrm{FVC} \%, \mathrm{FEV} 1$ (L), FEV1\% and FEV1/FVC (L)] of pulmonary ventilation function between the routine treatment group and anti GER group (all $\mathrm{P}>0.05$ ). Six months after treatment, all the aforementioned parameters increased in both the routine treatment and anti GER groups; and these parameters in the anti GER group were significantly higher compared to the value of the routine treatment group (all $\mathrm{P}<0.05$ ).

Anti GER treatment reduced inflammatory cytokines. Prior to the treatment, there was no significant difference detected in regard to the levels of inflammatory cytokines IL-13, IL-18, transforming growth factor- $\beta 1$ (TGF- $\beta 1$ ) and TNF- $\alpha$ between the routine treatment group and anti GER group (all $\mathrm{P}>0.05$ ). Six months after treatment, the levels of IL-13, IL-18, TGF- $\beta 1$ and TNF- $\alpha$ decreased in both the routine treatment and anti GER groups; and the levels of IL-13, IL-18, TGF- $\beta 1$ and TNF- $\alpha$ in the anti GER group were significantly lower compared to the levels observed in the routine treatment group (all $\mathrm{P}<0.05$; Fig. 2).

Anti GER treatment relieved inflammation. The total number of cells determined in the respective bronchoalveolar lavage fluid as well as the percentage of inflammatory cells between the two groups was compared (Table II). Before treatment, there was no significant difference observed in regard to the total number of cells in bronchoalveolar lavage fluid and percentage of inflammatory cells (monocyte, lymphocyte, eosinophil and neutrophil cells) (all $\mathrm{P}>0.05$ ). Compared with situation before treatment, the total number of inflammatory cells and the percentage of eosinophil cells significantly decreased with remarkable increases of monocyte, lymphocyte, and neutrophil cells observed in both groups 6 months after treatment (all $\mathrm{P}<0.05$ ). The total number of inflammatory cells and percentage of eosinophil cells in the anti GER group were remarkably lower than in the routine treatment group; however the percentages of monocyte, lymphocyte, and neutrophil cells were noticeably higher than in the routine group (all $\mathrm{P}<0.05$ ).

6MWD increased and times of AECOPD decreased of patients in the anti GER group. Prior to treatment, the patients in the routine treatment group and anti GER group displayed no significant differences in relation to 6MWD and AECOPD incidents (both $\mathrm{P}>0.05$ ). Six months after treatment, the patients in the routine treatment and anti GER groups exhibited increased 6MWD and decreased number of AECOPD incidents (both $\mathrm{P}<0.05$ ); while the patients in the anti GER group had longer 6MWD and lesser AECOPD incidents compared to the routine treatment group (both $\mathrm{P}<0.05$; Table III).

BODE index of patients decreased in the anti GER. The respective BODE indexes were evaluated for determination of the prognosis of patients with COPD (Table IV). There was no significant difference in the BODE index in the routine treatment group and the anti GER group prior the treatment $(\mathrm{P}>0.05)$. Six months after treatment, the BODE indexes had 
decreased significantly in both the routine treatment and anti GER groups (both $\mathrm{P}<0.05$ ); the BODE index was significantly lower in the anti GER group compared to the routine treatment group $(\mathrm{P}<0.05)$.

$B O D E$ index of patients was higher in the anti GER group with a longer course of disease and more AECOPD incidents. To further evaluate the relationship between the treatment effects and clinicopathological characteristics, the relationship between BODE index as well as the clinicopathological characteristics after treatment in the anti GER group were all analyzed, shown in Table V. The BODE index was found to be associated with the course of the disease and AECOPD incidents after treatment (both $\mathrm{P}<0.05$ ). The BODE index was confirmed to be higher with a longer course of disease and more AECOPD incidents. No significant difference was observed between the BODE index after treatment and parameters including age, gender, smoke, $\mathrm{BMI}, \mathrm{PaCO}_{2}, \mathrm{PaO}$ and plasma albumin.

\section{Discussion}

COPD is a widespread chronic disease associated with negative intra-thoracic pressure, increased respiratory center drive, as well as flat diaphragm. Exacerbation of COPD is widely considered to be the primary factor responsible for lowering the quality of life in patients and can contribute to deteriorating lung function. GER has more recently, been earmarked as a potential risk factor contributing to the exacerbation of COPD (18). There exists a high prevalence of GER among COPD patients. Likewise, patients with more GER symptoms are at a higher risk of suffering from COPD $(19,20)$. GER symptoms have been linked to COPD diagnoses and patients with GER suffered from increased frequency of exacerbations every year (21). Thus, the study investigated the relationship between anti-reflux treatment and inflammatory cytokines as well as the lung function change among patients with stable COPD along with GER.

Initially, the research successfully confirmed that pulmonary ventilation function in patients with COPD significantly improved after anti-reflux treatment. The overall results primarily demonstrated that FEV1, FEV1\% and FEV1/FVC remarkably decreased after anti-reflux treatment. Continuous gastric reflux material and aspiration can trigger lower airway inflammation and bronchospasm, and the reflux content has been shown to damage the respiratory epithelium, which can lead to various clinical manifestations associated with inflammatory effects (22). Phulpoto et al (23), reported that FEV1 had a significant association on the severity of airway obstruction with frequent gastroesophageal symptoms. These results were in concert with former findings that anti-reflux medication to be an important factor for objective tests and diagnostic confirmation of GER in patients with COPD. Another significant result suggested that the levels of IL-13, IL-18, TGF- $\beta 1$, and TNF- $\alpha$ in the sputum of patients with COPD significantly reduced. By evaluating the difference and the total number and distribution of inflammatory cells in bronchoalveolar lavage fluid before and 6 months after treatment, I found that anti GER treatment decreased the total number, with higher percentages of monocyte, lymphocyte, 
Table IV. BODE index between the routine treatment and anti GER groups before and 6 months after treatment.

\begin{tabular}{lcc}
\hline & & BODE index \\
\cline { 2 - 3 } Group & Before treatment & 6 months after treatment \\
\hline Routine treatment group & $2.47 \pm 0.50$ & $1.89 \pm 0.58$ \\
Anti GER group & $2.52 \pm 0.81$ & $1.15 \pm 0.73^{\mathrm{a}}$ \\
\hline aP<0.05 compared with the routine treatment group six months after treatment. BODE, Body mass index, obstruction, dyspnea, exercise; GER, \\
gastroesophageal reflux.
\end{tabular}

Table V. Relationship between BODE index and clinical pathology after treatment in the anti GER group.

\begin{tabular}{|c|c|c|c|c|c|}
\hline Variables & 0 & 1 & 2 & 3 & P-value \\
\hline Age (years) & & & & & 0.198 \\
\hline$\leq 55$ & 4 & 21 & 9 & 3 & \\
\hline$>55$ & 5 & 21 & 2 & 1 & \\
\hline Sex & & & & & 0.612 \\
\hline Male & 6 & 29 & 8 & 4 & \\
\hline Female & 3 & 13 & 3 & 0 & \\
\hline Course of disease (years) & $5.60 \pm 0.92$ & $6.42 \pm 1.54$ & $7.30 \pm 1.25$ & $7.64 \pm 0.96$ & $<0.001$ \\
\hline Smoke (yes/no) & $5 / 4$ & $31 / 11$ & $10 / 1$ & $2 / 2$ & 0.237 \\
\hline BMI & & & & & 0.525 \\
\hline$\leq 21$ & 3 & 19 & 6 & 3 & \\
\hline$>21$ & 6 & 23 & 5 & 1 & \\
\hline $\mathrm{PaCO}_{2}(\mathrm{mmHg})$ & & & & & 0.677 \\
\hline$\leq 40$ & 5 & 19 & 5 & 3 & \\
\hline$>40$ & 4 & 23 & 6 & 1 & \\
\hline $\mathrm{PaO}(\mathrm{mmHg})$ & & & & & 0.375 \\
\hline$\leq 60$ & 1 & 16 & 3 & 2 & \\
\hline$>60$ & 8 & 26 & 8 & 2 & \\
\hline Plasma albumin (g/l) & $34.27 \pm 0.71$ & $34.20 \pm 0.47$ & $34.15 \pm 0.54$ & $34.18 \pm 0.50$ & 0.654 \\
\hline Times of AECOPD (times/years) & $2.22 \pm 1.48$ & $2.60 \pm 1.06$ & $2.73 \pm 1.27$ & $3.00 \pm 2.45$ & $<0.001$ \\
\hline
\end{tabular}

BMI, body mass index; BODE, Body mass index, obstruction, dyspnea, exercise; AECOPD, acute exacerbation of chronic obstructive pulmonary disease; GER, gastroesophageal reflux.

and neutrophil cells and lower percentage of eosinophil cells. As previously described, inflammation was the largest factor responsible for the occurrence and progression of COPD (5). IL-13 is a key element in the stimulation of airway inflammation (24). During the progression of airway inflammation and structural remodeling, IL-13 was shown to cause reduplicated airway hyper-reactivity and chronic inflammation (25). The level of IL-13 significantly increased lung tissue based on a conducted by Crosby et al (26). IL-18 is mainly produced by monocytes and macrophages, which activates the release of toxic oxygen in neutrophils and macrophages (27). A previous study found that IL-18 was associated with the pathogenesis of COPD and played a crucial role in the inflammation in patients with COPD (28). Airway remodeling is characterized by continuous asthma, including increased airway smooth muscle (ASM) mass and altered extracellular matrix (ECM) deposition. Interestingly, a significant association between TGF- $\beta 1$ and airway remodeling on patients with COPD was observed, which might be induced by high-expression of TGF- $\beta 1$ consequently increased the thickness of airway and basement membrane, which furthermore promoted fibronectin from human ASM cells and deposition of ECM proteins (29). TNF- $\alpha$, as a pro-inflammatory cytokine operating at an early stage of the inflammatory cascade, has been reported to be a central player in the occurrence of COPD and is again increased when patients are in the process of suffering from an acute exacerbation attack (30). Eagan et al (31), highlighted that higher TNF- $\alpha$ level in patients with COPD was responsible for the pathogenesis of COPD and associated comorbidities. The protection against GORD has also been reported to result in 
the inhibition of the pro-inflammatory process (32). The aforementioned information highlighted that anti-reflux treatment could reduce the incidence of airway inflammation, which significantly reduced the levels of the inflammatory cytokines IL-13, IL-18, TGF- $\beta 1$, TNF- $\alpha$ amongst patients with COPD as well as the total number of inflammatory cells.

Another significant observation of the study was that anti-reflux treatment improved the prognosis of patients with COPD. The 6MWT is a simple test for patients with COPD, which could be potentially employed as a useful reference in lung function and depression (33). After anti-reflux treatment, the pulmonary ventilation function improved amongst patients with COPD, along with a reduction in the amount of acute attacks, which consequently increased 6MWD. BMI, airflow obstruction, dyspnoea and patient exercise capacity index belong to the multidimensional grading system to predict the risk of death in patients with COPD and reflect disease severity (34). Hence, the BODE index relatively decreased due to improved lung function of patients and decreased levels of inflammatory cytokines.

To conclude, the study presented evidence providing verification that anti-reflux treatment could improve pulmonary ventilation function and prognosis of patients with COPD combined with GER, and decrease the levels of IL-13, IL-18, TGF- $\beta 1$ and TNF- $\alpha$, which was indicative of the effectiveness of anti-reflux treatment in COPD therapy. However, more prospective studies with causation in the future are needed to focus on developing new therapeutic strategies for treating COPD with GER. There were some limitations faced during the study. This study did not include a well-devised follow-up plan. Therefore, I intended to perform a 2-5 years follow-up to further investigate the long-term prognosis after GER treatment. The details of the follow-up plan are as follows: Follow-up method is an outpatient visit; follow-up contents include follow-up rate and lost follow-up rate of all patients, and basic safety indexes including vital signs, hematuria routine, blood biochemistry and pulmonary function test; asking adverse reactions and combined use of drugs over a period of 2 years. The present study had a relatively small sample size, and as a result a larger sample size study is required in order to confirm the reliability of the results.

\section{Acknowledgements}

The author wishes to express his gratitude to reviewers for their critical comments.

\section{Funding}

No funding was received.

\section{Availability of data and materials}

The datasets used and/or analyzed during the current study are available from the corresponding author on reasonable request.

\section{Author contribution}

HL conceived and designed the study, was involved in data collection, performed the statistical analysis and preparation of figures and drafted the paper. HL also contributed substantially to its revision.

\section{Ethics approval and consent to participate}

All participating subjects signed informal written consent documents. The present study was performed with the approval of the Ethical Committee of the People's Hospital of Guangxi Zhuang Autonomous Region.

\section{Consent for publication}

Consent for publication was obtained from the participants.

\section{Competing interests}

The author declares that they have no competing interests.

\section{References}

1. Delzell JE Jr: Common lung conditions: Chronic obstructive pulmonary disease. FP Essent 409: 23-31, 2013.

2. Vestbo J, Hurd SS, Agusti AG, Jones PW, Vogelmeier C, Anzueto A, Barnes PJ, Fabbri LM, Martinez FJ, Nishimura M, et al: Global strategy for the diagnosis, management, and prevention of chronic obstructive pulmonary disease: GOLD executive summary. Am J Respir Crit Care Med 187: 347-365, 2013.

3. Iyer Parameswaran G and Murphy TF: Chronic obstructive pulmonary disease: Role of bacteria and updated guide to antibacterial selection in the older patient. Drugs Aging 26: 985-995, 2009.

4. Lee H, Kim J and Tagmazyan K: Treatment of stable chronic obstructive pulmonary disease: The GOLD guidelines. Am Fam Physician 88: 655-663, 663B-F, 2013.

5. Gan WQ, Man SF, Senthilselvan A and Sin DD: Association between chronic obstructive pulmonary disease and systemic inflammation: A systematic review and a meta-analysis. Thorax 59: 574-580, 2004.

6. Casanova C, Baudet JS, del Valle Velasco M, Martin JM, Aguirre-Jaime A, de Torres JP and Celli BR: Increased gastro-oesophageal reflux disease in patients with severe COPD. Eur Respir J 23: 841-845, 2004.

7. Rogha M, Behravesh B and Pourmoghaddas Z: Association of gastroesophageal reflux disease symptoms with exacerbations of chronic obstructive pulmonary disease. J Gastrointestin Liver Dis 19: 253-256, 2010.

8. Liang BM and Feng YL: Association of gastroesophageal reflux disease symptoms with stable chronic obstructive pulmonary disease. Lung 190: 277-282, 2012.

9. Wang AJ, Liang MJ, Jiang AY, Lin JK, Xiao YL, Peng S, Chen J, Wen WP and Chen MH: Gastroesophageal and laryngopharyngeal reflux detected by 24-hour combined impedance and $\mathrm{pH}$ monitoring in healthy Chinese volunteers. J Dig Dis 12: 173-180, 2011.

10. Yeh AM and Golianu B: Integrative treatment of reflux and functional dyspepsia in children. Children (Basel) 1: 119-133, 2014.

11. Ingebrigtsen TS, Marott JL, Vestbo J, Nordestgaard BG, Hallas J and Lange P: Gastro-esophageal reflux disease and exacerbations in chronic obstructive pulmonary disease. Respirology 20: 101-107, 2015.

12. Benson VS, Müllerová H, Vestbo J, Wedzicha JA, Patel A and Hurst JR; Evaluation of COPD Longitudinally to Identify Predictive Surrogate Endpoints (ECLIPSE) Investigators: Associations between gastro-oesophageal reflux, its management and exacerbations of chronic obstructive pulmonary disease. Respir Med 109: 1147-1154, 2015.

13. Lundell LR, Dent J, Bennett JR, Blum AL, Armstrong D, Galmiche JP, Johnson F, Hongo M, Richter JE, Spechler SJ, et al: Endoscopic assessment of oesophagitis: Clinical and functional correlates and further validation of the Los Angeles classification. Gut 45: 172-180, 1999.

14. Holub JL, Silberg DG, Michaels LC, Williams JL, Morris CD and Eisen G: Acid-related upper endoscopy findings in patients with diabetes versus non-diabetic patients. Dig Dis Sci 55: 2853-2859, 2010 
15. Kumbhari V, Familiari P, Bjerregaard NC, Pioche M, Jones E, Ko WJ, Hayee B, Cali A, Ngamruengphong S, Mion F, et al: Gastroesophageal reflux after peroral endoscopic myotomy: A multicenter case-control study. Endoscopy 49: 634-642, 2017.

16. Calik-Kutukcu E, Savci S, Saglam M, Vardar-Yagli N Inal-Ince D, Arikan H, Aribas Z, Ozer O, Bosnak-Guclu M and Coplu L: A comparison of muscle strength and endurance, exercise capacity, fatigue perception and quality of life in patients with chronic obstructive pulmonary disease and healthy subjects: A cross-sectional study. BMC Pulm Med 14: 6, 2014.

17. Williams JE, Green RH, Warrington V, Steiner MC, Morgan MD and Singh SJ: Development of the i-BODE: Validation of the incremental shuttle walking test within the BODE index. Respir Med 106: 390-396, 2012.

18. Kim J, Lee JH, Kim Y, Kim K, Oh YM, Yoo KH, Rhee CK, Yoon HK, Kim YS, Park YB, et al: Association between chronic obstructive pulmonary disease and gastroesophageal reflux disease: A national cross-sectional cohort study. BMC Pulm Med 13: 51, 2013.

19. Gadel AA, Mostafa M, Younis A and Haleem M: Esophageal motility patternand gastro-esophageal refluxinchronicobstructive pulmonary disease. Hepatogastroenterolog y 59: 2498-2502, 2012.

20. Takada K, Matsumoto S, Kojima E, Iwata S, Okachi S, Ninomiya K, Morioka H, Tanaka K and Enomoto Y: Prospective evaluation of the relationship between acute exacerbations of COPD and gastroesophageal reflux disease diagnosed by questionnaire. Respir Med 105: 1531-1536, 2011.

21. Sakae TM, Pizzichini MM, Teixeira PJ, Silva RM, Trevisol DJ and Pizzichini E: Exacerbations of COPD and symptoms of gastroesophageal reflux: A systematic review and meta-analysis. J Bras Pneumol 39: 259-271, 2013 (In English, Portuguese).

22. Pacheco-Galván A, Hart SP and Morice AH: Relationship between gastro-oesophageal reflux and airway diseases: The airway reflux paradigm. Arch Bronconeumol 47: 195-203, 2011.

23. Phulpoto MA, Qayyum S, Rizvi N and Khuhawar SM: Proportion of gastroesophageal reflux symptoms in patients with chronic obstructive pulmonary disease. J Pak Med Assoc 55: 276-279, 2005.

24. Oh CK, Geba GP and Molfino N: Investigational therapeutics targeting the IL-4/IL-13/STAT-6 pathway for the treatment of asthma. Eur Respir Rev 19: 46-54, 2010.
25. Hashimoto K, Sheller JR, Morrow JD, Collins RD, Goleniewska K, O'Neal J, Zhou W, Ji S, Mitchell DB, Graham BS and Peebles RS Jr: Cyclooxygenase inhibition augments allergic inflammation through CD4-dependent, STAT6-independent mechanisms. J Immunol 174: 525-532, 2005.

26. Crosby LM and Waters CM: Epithelial repair mechanisms in the lung. Am J Physiol Lung Cell Mol Physiol 298: L715-L731, 2010.

27. van de Veerdonk FL, Netea MG, Dinarello CA and Joosten LA: Inflammasome activation and IL-1 $\beta$ and IL-18 processing during infection. Trends Immunol 32: 110-116, 2011.

28. Dima E, Koltsida O, Katsaounou P, Vakali S, Koutsoukou A, Koulouris NG and Rovina N: Implication of Interleukin (IL)-18 in the pathogenesis of chronic obstructive pulmonary disease (COPD). Cytokine 74: 313-317, 2015.

29. Johnson PR, Burgess JK, Ge Q, Poniris M, Boustany S, Twigg SM and Black JL: Connective tissue growth factor induces extracellular matrix in asthmatic airway smooth muscle. Am J Respir Crit Care Med 173: 32-41, 2006.

30. von Haehling S Hopkinson NS, Polkey MI, Niethammer M, Anker SD and Genth-Zotz S: Elevated TNFalpha production in whole blood in patients with severe COPD: The potential link to disease severity. Wien Klin Wochenschr 121: 303-308, 2009.

31. Eagan TM, Ueland T, Wagner PD, Hardie JA, Mollnes TE, Damås JK, Aukrust $\mathrm{P}$ and Bakke PS: Systemic inflammatory markers in COPD: Results from the Bergen COPD cohort study. Eur Respir J 35: 540-548, 2010

32. Shahabi S, Rasmi Y, Jazani NH and Hassan ZM: Protective effects of Helicobacter pylori against gastroesophageal reflux disease may be due to a neuroimmunological anti-inflammatory mechanism. Immunol Cell Biol 86: 175-178, 2008.

33. Polkey MI, Spruit MA, Edwards LD, Watkins ML, Pinto-Plata V, Vestbo J, Calverley PM, Tal-Singer R, Agusti A, Bakke PS, et al: Six-minute-walk test in chronic obstructive pulmonary disease: Minimal clinically important difference for death or hospitalization. Am J Respir Crit Care Med 187: 382-386, 2013.

34. Hernandes NA, Wouters EF, Meijer K, Annegarn J, Pitta F and Spruit MA: Reproducibility of 6-minute walking test in patients with COPD. Eur Respir J 38: 261-267, 2011. 